\title{
Strategic Intuition Capability toward Performance of Entrepreneurs: Evidence from Thailand*
}

\author{
Somnuk AUJIRAPONGPAN ${ }^{1}$, Jintanee RU-ZHE ${ }^{2}$, Jaturon JUTIDHARABONGSE ${ }^{3}$
}

Received: March 17, 2020 Revised: March 28, 2020 Accepted: May 01, 2020

\begin{abstract}
The objective of this research is to study the confirmative components of strategic intuition capability and the study of causal influence between strategic intuition capability and firm performance of SMEs in Thailand. The consistency method, structural equation models and empirical data were used to test the influential factors on firm performance. Models were then proposed for the development of the strategic intuition capability of entrepreneurs in Thailand. The research sample consisted of 342 SME provincial champion entrepreneurs listed with Thailand's Office of Small and Medium Enterprises. The research results reveal that the model of strategic intuition capability responded well to the empirical data. Additionally, a relationship was identified between firm performance and the causal influence of the strategic intuition capability of entrepreneurs. In accordance with the empirical data, the strategic intuition capability of entrepreneurs had a significant causal influence on firm performance $($ Chi-square $=35.71, \mathrm{df}=25, \mathrm{P}$-value $=0.07615, \mathrm{GFI}=0.98, \mathrm{AGFI}=0.96, \mathrm{RMSEA}=$ $0.033, \mathrm{RMR}=0.027)$. Furthermore, with respect to the development of strategic intuition capability, the development of genuine wisdom based on systematic knowledge management achieved via conscious mental concentration may lead to the next stage of strategic intuition.
\end{abstract}

Keywords : Strategic Intuition Capability, Knowledge Management, Firm Performance, Entrepreneur, SMEs, Thailand.

JEL Classification Code: M40, O15, O31.

\section{Introduction}

The organizations and businesses of today focus on using knowledge as the basis for their business strategies (knowledge-based view). Therefore, the development of the knowledge resources, which are essential to the organization and are in accordance with the organization's plans and goals

\footnotetext{
*This research was partially supported by the new strategic research (P2P) project, Walailak University, Thailand. And it also was supported by Institute of Research and Innovation, Walailak University.

${ }^{1}$ First Author and Corresponding Author. Associate Professor, Walailak Management School, Walailak University, Thailand [Postal Address: School of Management Academic Building 3, Walailak University, 222 Thai Buri, Tha Sala, Nakhon Si, Thammarat, 80160, Thailand] Email: asomnuk@wu.ac.th

${ }^{2}$ Lecturer, Walailak Management School, Walailak University, Thailand. Email: jjintane@wu.ac.th

${ }^{3}$ Researcher, PhD Candidate, Walailak Management School, Walailak University, Thailand. Email: cjaturon@wu.ac.th

() Copyright: The Author(s)

This is an Open Access article distributed under the terms of the Creative Commons Attribution Non-Commercial License (http://Creativecommons.org/licenses/by-nc/4.0/) which permits unrestricted noncommercial use, distribution, and reproduction in any medium, provided the original work is properly cited.
}

to create a sustainable and long-term competitive advantage, must be the organization's primary focus (Barney, 1991; Kogut \& Zander, 1992). Haggie and Kingston (2003) examined the strategies of knowledge management used by organizations and identified three important focal points, namely, knowledge focus, business process focus and endresult focus. Importantly, to be successful, the formulation of knowledge management strategies must be consistent and aligned with the organization's business strategies (Zack, 1999; Greiner, Bohmann \& Krcmar, 2007). Furthermore, the form and focal point of knowledge management strategies are dependent on the environment, context and goals of the organization (Haggie \& Kingston, 2003).

Over the past 40 years, studies on the business strategies of entrepreneurs have focused on the strategic development of long-term performance (Meers \& Robertson, 2007; Miller \& Cardinal, 1994; Venkatraman \& Ramanujam, 1986), a challenging accomplishment in the context of fluctuating business environments (Grant, 2003). Some academics have suggested that changes in a fluctuating environment require a flexible and constructive strategic development plan (Hamel, 1996) and a proactive, continuous and diverse 
organizational management process (Brown \& Eisenhardt, 1997). Some studies have also discussed strategies implemented in organizations. Although there have been efforts to change the environment, as well as the actions and attitudes of the individuals within the organization, it is essential that more be known about the decisions and actions of individuals involved in organizational processes, especially with respect to the feelings, instincts and intuitions of the people in the organization. As evidenced from the research trends since 2000, researchers have emphasized the study of strategy under the concept of intuition. This emphasis on intuition is continuously increasing, which explains the changes in the concentration of studies on strategy (Teece, 2018)

Based on the previous knowledge management concepts, it is concluded that the majority of the research has focused on the study of specific issues in a modular way, whether it be from an individual context related to the process of knowledge management or from an organizational context, which is a component of those factors that facilitate knowledge management. According to the research, entrepreneurs, who value the integration of intellectual resources through knowledge management processes and the conduct of basic organizational training activities, increase their competitive advantages (Crossan, Lane, \& White, 1999). To facilitate knowledge management processes, Gannon, Lynch and Harrington (2009) developed the dynamic knowledge management capability model. In accordance with this model, succeeding in business requires the organization to adopt critical priority factors, including perspectives, ideas and decision-making processes when choosing strategies to address organizational problems, eliminate defects and design plans that align with the organization's vision (Kouzes \& Posner, 2012; Duggan, 2013).

One of the key capabilities of successful business entrepreneurs is the ability to recognize future business possibilities that are consistent with the goals of the entrepreneur without having to rely on predictions or apply rational information to make decisions, but rather rely on feelings and instincts combined experience when making decisions (Teece, 2018; Yi, Han, \& Cha, 2018). In other words, the most successful entrepreneurs possess an instinct for clear and accurate decision-making and recognize crises and opportunities before others in the business. Such capabilities are referred to as wisdom or insight. Hence, this study seeks to identify the important components of these unique capabilities and find ways to develop such capabilities with the aims to increase the business potential of Thai entrepreneurs and enhance the competitive advantages of businesses in Thailand, while conforming with government policies and with the goal being to bring the country to Thailand 4.0.

\section{Literature Review}

\subsection{Strategic Intuition Capability}

The new paradigm of leadership education in the $21 \mathrm{st}$ century is on the focus of strategic leaders as they are being encouraged to look to the future and create new challenges (Srichan, Tachaphahapong, \& Methakunavudhi, 2016). This focus will provide leaders with the opportunity to select the optimal strategies to address the organization's problems, eliminate weaknesses, and align their work with the organization's vision (Kouzes \& Posner, 2012; Duggan, 2013). It is posited that a superior leader possesses the unique ability to perceive possibilities (Aujirapongpan \& Hareebin, 2020) and that strategic intuition is the mind's way of perceiving these possibilities and making timely decisions based on the knowledge gained from experience. Through intuition, premonition also allows one to perceive certain future events (Miller \& Ireland, 2005). Duggan (2013) offered this definition of strategic intuition. Strategic intuition is a scientific phenomenon that occurs from the use of good ideas and reasoning through past experiences to solve problems in the future that have never been seen before (Ahangaran, Khooshebast \& Vahedi, 2016).

Similarly, Dane and Pratt (2007) described strategic intuition as a form of brain processing in an easy-to-use format. Such processing occurs beyond conscious thinking and promotes a holistic connection through environmental stimulation. Over the past decades, studies on intuition have been advanced in the field of behavioral science and have expanded the scope of such research to the branch of social neurology. Specifically, Hodgkinson, Smith, Burke, Claxton and Sparrow (2009), Aujirapongpan and Jutidharabongse (2017) have identified key elements for organizational executives to enhance their intuition capabilities, namely, the acquisition of intuition expertise, the development of selfawareness, the management of strategic decision-making, and the creating of situations.

Strategic intuition capability is described as the personal ability or talent ability to make decisions regarding a specific subject by employing one's thought processes, engaging through concentration and an alert state of mind, and possessing the proper foundation based on job expertise and analytical competency (Nocker \& Sena, 2019). Accordingly, the intellectual pathway is divided into three areas, namely, systematic attention (Payutto, 2003), acquisition of intuitive expertise (Hodgkinson et al., 2009) and mental concentration (Payutto, 2012).

\subsection{Firm Performance}

It is important in today's world that organizations evaluate and analyze their performances and operations and compare 
the results of those analyzed with the analysis from previous years (Ha, 2020). Currently, the organization's performance appraisal system is not just an inspection

system, but rather, it is a system that guides the organization as it strives to achieve its established goals. Hence, the evaluation of firm performance has changed dramatically from the past and will continue to change as organizations move towards the future. For example, today, many organizations demonstrate significant increases in performance as the result of the development of a performance measurement system that understands and aligns with firm performance. The public and private sectors have used performance appraisals as management tools for years as a way to determine the effectiveness and efficiency of the production process of products and services and as a means to increase strengths and identify weaknesses must be addressed.

With respect to today's Thailand, every organization, whether it be a nonprofit or a nonprofit organization, has evaluated its performance, as all organizations, i.e., small, medium, and large, want to know how they compare to their competitors with respect to performance. Therefore, it is not surprising to see a tremendous increase in performance metrics, especially with respect to financial measures, which are the main targets of business organizations because they are printed in newspapers, journals and annual reports and are, thus, available to the public. In addition to financial measures, there are many non-financial measures that have been introduced, such as customer satisfaction instruments, instruments measuring the rate of waste generated by an organization's production system and even tools that assess the speed of new product development in the market. That said, there is no consensus regarding the definition of a performance measurement system as it relates to organizations. For example, Monica, Mike, Pretro, Veronica, Bernard, Dina and Andy (2007), with the intent of employing an appraisal system, conducted a study to determine the definition adopted by researchers, arguing that a common, accepted definition of a performance measurement system for organizations would certainly increase the ease and accuracy of conducting comparisons of research results. Instead, they found that because there is no single acceptable definition of the concept, it is extremely difficult to compare research results. According to the QUOTE research, which reviews the literature related to the definition of performance measurement systems for organizations, it is concluded that the interpretation of the performance system of organizations is divided into three categories, namely, the nature of the organization's performance measurement system, the role of the organization's performance measurement system and the process that is part of the organization's performance measurement system.
Rompho (2018), after studying the financial success of organizations, divided financial success into two types, specifically, organizational operational success as determined by measuring the profits of the organization that are created using the existing resources of the current organization and applying the marketing sense that focuses on the value of the organization from the perspective of the investor. This value is based on the organization's financial performance indicators. Specifically, the return on assets (ROAs) is a measure of the net profit of the organization divided by the average assets that the organization holds during that year. This measure reflects the efficiency of using assets of the organization to create profits; earnings per share is calculated from the profits that the organization has divided by the total number of shares of the organization; and economic value added is a measure calculated from the net operating profits after taxes are deducted according to capital charge and calculated from the product of the cost of capital and the investment capital.

For measuring the performance of financial organizations in this research, the organization's performance measurement tool was used to assess the ROAs based on the net profits of the organization divided by the average assets of the organization. Because the business group in this study is a small SME group, i.e., a business group that has not yet raised funds through shares in the stock market, it is suitable to use the measurement of assets model to assess the performance of the organization.

Covin and Miles (1999) found that entrepreneurs with good performance records have a positive impact on organizational performance, a finding supported by Bai (2010), who determined that strong firm performance was the result of having high quality entrepreneurs. The positive impacts of quality entrepreneurs include improvements in the purchase of products or services that better meet customer needs and increase competitiveness, increases in sales and profits for entrepreneurs, and reductions in expenses incurred due to raw material costs and operating costs. Accordingly, this study advances the hypothesis that there is a direct relationship between the strategic intuition capabilities of entrepreneurs (see Figure 1).

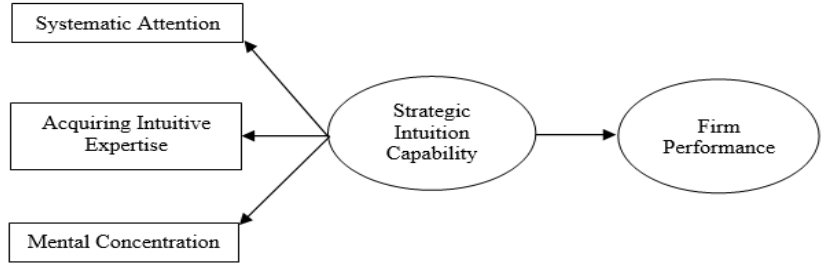

Figure 1: Conceptual Framework 


\section{Research Methods and Materials}

\subsection{Population and Sampling}

The database of SMEs compiled by the SME Provincial Champions 2018 Project and listed with Thailand's Office of Small and Medium Enterprises was used to identify the entrepreneurs for this study. The initial sample size consisted of 450 cases (Export-Import Bank of Thailand, 2018), and hence, the questionnaire was sent to all 450 identified businesses with weekly follow-ups for one month in an effort to maximize participation. At the end of the specified period, $342(76 \%)$ of the respondents had replied. Accordingly, the sample was divided into groups based on the demographic data of the entrepreneurs as presented in Table 1.

The results of the analysis of the personal characteristics of the entrepreneurs in the sample group are detailed in Table 1. As evidenced in the table, the majority of the respondents, $225(65.8 \%)$, were male, $131(38.3 \%)$ were between 41 and 50 years of age, and $162(47.4 \%)$ held bachelor's degrees. Furthermore, of the responding entrepreneurs, 148 (43.3\%) had between five and ten years of experience working in the business.

The results of the business data analysis of the sampled entrepreneurs, as presented in Table 2, indicate that the majority of businesses, $203(62.1 \%)$ operate food and beverage establishments, followed by tourism and accommodation at $50(14.6 \%)$. The details of the businesses in the study are as follows: $43.3 \%$ (148) have operation periods between five and 10 years, and $36.8 \%$ (126) have operation periods between 11 and 15 years. In addition, 214 $(62.6 \%)$ businesses have fewer than 50 employees, while 107 business $(31.3 \%$ ) have between 51 and 200 people. With respect to investments in business operations, 89 respondents $(45.6 \%)$ have investments of less than 10 million baht, and 124 respondents $(36.3 \%)$ have investments between 10 and 50 million baht, and with respect to ROAs, 137 respondents (40.1\%) have ROAs of less than 25\%, followed by 117 respondents (34.2\%) with ROAs between 25 and 50\%.

\subsection{Data Analysis}

The questionnaire/survey method with a 5-level Likert scale was used for this study, and the SPSS software program was used to analyze basic statistical values such as frequency, percentage, mean, standard deviation, Chisquare, and alpha coefficients. Pearson's correlation coefficient, KMO statistics and Bartlett's sphericity test were used to consider the characteristics of the respondents and to analyze the relationships between various components from the empirical data of entrepreneurs in Thailand based on the research hypothesis regarding structural equation modelling and with respect to the Pearson correlation analysis and the path analysis of the congeneric measurement model. The statistical values used to check the consistency of the research model and the empirical data based on the research hypothesis include Chi-square, goodness of fit index (GFI) and adjusted goodness of fit index (AGFI)

The analysis of the confirmatory elements of strategic intuition capability is aimed at testing the consistency of a pattern, while the relationship structure of the model of strategic intuition capability using the empirical data as the preliminary data to study the relationship between the strategic intuition capability of entrepreneurs in Thailand and firm performance was used. For the analysis of the confirmed components of strategic intuition capability and to determine the degree of importance of each element, the factor analysis technique was used to study the three subelements, i.e., systematic attention, acquisition of intuitive expertise and mental concentration.

Table 3 reveals that the Kaiser-Meyer-Olkin measure of sampling adequacy (MSA) of strategic intensity is 0.811 , which is greater than 0.80 , indicating that the composition is very good. The Bartlett's test of sphericity exhibited a value of 7123.692 with a probability of 0.000 and statistical significance at the level of .01, indicating that the variables are related and can be analyzed for composition (Hair, Black, Babin \& Anderson, 2014) This study examines the identification of only one value of the model (identification of the model) to study the characteristics of unknown parameter values in the research model and determine whether they meet the conditions of the analysis. The results indicate that an over identification condition can also estimate the various parameters in the model and estimate the SE value and t-value, thus suggesting that the model can use the LISREL program to analyze data.

Table 1: Personal characteristics of the entrepreneurs

\begin{tabular}{|l|c|c|c|}
\hline \multicolumn{2}{|c|}{ status } & frequency & percent \\
\hline Gender & Male & 225 & 65.8 \\
\hline Age & Female & 117 & 34.2 \\
\hline & $<30$ years & 57 & 16.7 \\
\hline & $30-40$ years & 90 & 26.3 \\
\hline & $41-50$ years & 131 & 38.3 \\
\hline Education & High school & 36 & 18.7 \\
\hline & Bachelor's & 162 & 47.4 \\
\hline & Master's & 126 & 36.5 \\
\hline & Doctorate & 18 & 5.3 \\
\hline Business- & $<5$ years & 27 & 7.9 \\
\hline Experience & $5-10$ years & 148 & 43.3 \\
\hline & $11-15$ years & 126 & 36.8 \\
\hline & $>15$ years & 41 & 12.0 \\
\hline
\end{tabular}


Table 2: Business data of entrepreneurs

\begin{tabular}{|c|c|c|c|}
\hline \multicolumn{2}{|c|}{ Business } & \multirow{2}{*}{$\begin{array}{c}\text { frequency } \\
203\end{array}$} & \multirow{2}{*}{$\begin{array}{c}\text { percent } \\
62.1\end{array}$} \\
\hline Business type & Food \& drink & & \\
\hline & Clothes & 41 & 12.0 \\
\hline & Tourism \& accommodation & 50 & 14.6 \\
\hline & Health \& beauty & 23 & 6.7 \\
\hline & Jewellery & 16 & 4.7 \\
\hline & Appliance & 8 & 2.3 \\
\hline & Electronics & 1 & 0.3 \\
\hline \multirow[t]{4}{*}{ Business age } & $<5$ years & 27 & 7.9 \\
\hline & $5-10$ years & 148 & 43.3 \\
\hline & $11-15$ years & 126 & 36.8 \\
\hline & $>15$ years & 41 & 12.0 \\
\hline Number of & $<50$ people & 214 & 62.6 \\
\hline \multirow[t]{2}{*}{ employees } & $51-200$ people & 107 & 31.3 \\
\hline & $>200$ people & 21 & 6.1 \\
\hline \multirow[t]{3}{*}{ Investment } & $<10$ million & 178 & 52.0 \\
\hline & $10-50$ million & 124 & 36.3 \\
\hline & $51-200$ million & 40 & 11.7 \\
\hline \multirow[t]{4}{*}{ Return on assets } & $<25 \%$ & 137 & 40.1 \\
\hline & $25-50 \%$ & 117 & 34.2 \\
\hline & $51-75 \%$ & 16 & 4.7 \\
\hline & $>75 \%$ & 72 & 21.1 \\
\hline
\end{tabular}

Table 3: Kaiser-Meyer-Olkin measure of sampling adequacy (MSA) and Bartlett's test of sphericity of strategic intuition capability

\begin{tabular}{|l|c|c|c|c|}
\hline & $\begin{array}{c}\text { Kaiser-Meyer-Olkin Measure of } \\
\text { Sampling Adequacy }\end{array}$ & P-value & $\begin{array}{c}\text { Bartlett's Test of } \\
\text { Sphericity }\end{array}$ & df \\
\hline $\begin{array}{l}\text { Strategic Intuition } \\
\text { Capability }\end{array}$ & 0.811 & 0.000 & 7123.692 & 725 \\
\hline
\end{tabular}

Table 4: The results of the confirmation component analysis, construct reliability $(\rho C)$ of latent variables and average variance extracted $\left(\rho_{\mathrm{v}}\right)$ of the strategic intuition capability model

\begin{tabular}{|c|c|c|c|c|c|c|c|}
\hline \multicolumn{2}{|c|}{ The element } & Indicator & $\begin{array}{c}\text { Weight } \\
\text { Element (b) }\end{array}$ & $\begin{array}{c}\text { Standard } \\
\text { Deviation (SE) }\end{array}$ & $\begin{array}{c}\text { Test Statistics } \\
\text { (t-test) }\end{array}$ & $\begin{array}{c}\text { Construct } \\
\text { Reliability }(\rho C)\end{array}$ & $\begin{array}{c}\text { Average Variance } \\
\text { Extracted }\left(\rho_{\mathrm{v}}\right)\end{array}$ \\
\hline \multirow{3}{*}{\multicolumn{2}{|c|}{ SIC }} & SYA & 0.35 & 0.05 & $9.97^{* *}$ & 0.7517 & 0.2769 \\
\hline & & AIE & 0.42 & 0.03 & $7.42^{* *}$ & 0.8046 & 0.3560 \\
\hline & & MEC & 0.34 & 0.04 & $11.22^{* *}$ & 0.8756 & 0.4402 \\
\hline \multicolumn{8}{|c|}{ Consistency Check Index } \\
\hline$\chi^{2}$ & df & $\mathrm{P}$-value & $\chi^{2} / \mathrm{df}$ & GFI & AGFI & RMSEA & RMR \\
\hline 262.53 & 324 & 0.996 & 0.81 & 0.93 & 0.92 & 0.000 & 0.033 \\
\hline
\end{tabular}

** $(\mathrm{P}<.01)$ 


\section{Results and Discussion}

The confirmatory element analysis using the LISREL program of strategic intuition capability consists of three sub-components. The results of the analysis revealed that the findings from the first data analysis were not consistent with the empirical data. Accordingly, the model was adjusted until the results were consistent with the empirical data. The Chi-square, P-value, GFI, AGFI, RMSEA and RMR values are presented in Table 4 and Figure 2.

As indicated, the Chi-square is 262.53 at the independence layer of 324 and exhibits a probability value of 0.996 . When the Chi-square value is divided by the independence layer, the result is 0.81 with a coefficient index (GFI) of 0.93 and a modified coordination level (AGFI) of 0.92 . The second mean estimation error (RMSEA) is 0.000 , and the mean square root index (RMR) is 0.033 . As the results are consistent with the data, the research model is deemed acceptable. It was further found that all three sub-elements of strategic insight are positive with the lowest to highest values ranging from 0.34 to 0.42 , respectively, and exhibiting statistical significance at the 0.01 level. Of the three sub-elements, acquiring intuitive expertise (AIE), with a weight of the components at 0.42 , is concluded to be the most important. AIE is followed by systematic attention (SYA) and mental concentration (MEC) with composition weights of 0.35 and 0.34 , respectively. The efficiency of the measurement model is evaluated by considering the validity, which is the ability of the indicators to measure latent variables in the model based on the significance of the component weights, the precision (reliability) of the measurements, i.e., their consistency, the reliability of the latent variables (construct reliability: $\rho \mathrm{C}$ ) and the mean of the variance (average variance extracted (AVE): $\rho v$ )
The validity analysis reveals that the element weights of the latent variables are significant in all components ( $\mathrm{t}$-value $>|1.96|$ ), supporting the validity of the measurement, as presented in Table 4, and indicating that the precision of the lowest latent variable to the highest latent variable ranges from 0.7517 to 0.8756 , respectively. Furthermore, the high precision value is $\rho \mathrm{C}>0.60$, and the AVEs, from lowest to highest, range from 0.2769 to 0.4402 , while the MEC element explains the variance of the variables in the components greater than other elements $(\rho \mathrm{v}>0.50)$.

Analysing the causal influence to study the relationship of structural equations, it is determined that the variables used in the analysis exhibit the characteristics of normal distribution (normality). The distribution of the variables is assessed by testing the significance of skewness and kurtosis using LISREL. The findings indicate that the strategic intuition capability (SIC), which has an effect on firm performance (FP), has an abnormal distribution with statistical significance at the level of 0.05 . Furthermore, the model and empirical data reveal that the results of the model analysis are consistent with reliable data, although some variables may exhibit abnormal distribution characteristics, as in Table 5.

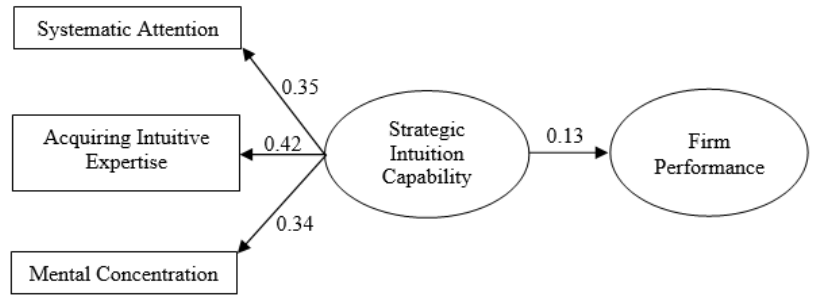

Figure 2: The structural equation model

Table 5: Distribution of the relationships of variables

\begin{tabular}{|l|c|c|c|c|c|c|}
\hline \multirow{2}{*}{ Variables } & \multicolumn{2}{|c|}{ Skewness } & \multicolumn{2}{c|}{ Kurtosis } & \multicolumn{2}{c|}{ Skewness and Kurtosis } \\
\cline { 2 - 7 } & Z-score & P-value & Z-score & P-value & Chi-square & P-value \\
\hline SIC & 0.154 & 0.137 & 1.406 & 0.734 & 7.505 & 0.028 \\
\hline FP & -2.477 & 0.013 & 0.699 & 0.077 & 10.748 & 0.326 \\
\hline
\end{tabular}

Table 6: Distribution validity analysis

\begin{tabular}{|c|c|c|c|c|c|c|}
\hline \multirow{2}{*}{ Construct } & \multicolumn{2}{|c|}{ Cross Construct Correlation } & \multirow{2}{*}{ Mean } & \multirow{2}{*}{ S.D. } & \multirow{2}{*}{$\rho \mathbf{C}$} & \multirow{2}{*}{$\rho v$} \\
\hline & SIC & FP & & & & \\
\hline SIC & 1.00 & & 3.52 & 0.387 & 0.7671 & 0.6329 \\
\hline FP & 0.12 & 1.00 & 2.07 & 1.135 & 0.5896 & 0.5270 \\
\hline
\end{tabular}


Table 7: Causal influences

\begin{tabular}{|c|c|c|c|c|c|c|c|}
\hline \multicolumn{2}{|c|}{ Dependent Variables } & \multicolumn{2}{|c|}{$\mathbf{R}^{2}$} & \multicolumn{2}{|c|}{ Influences } & \multicolumn{2}{|c|}{ Independent Variables (SIC) } \\
\hline \multicolumn{2}{|l|}{ SIC } & \multicolumn{2}{|c|}{0.57} & \multicolumn{2}{|c|}{$\mathrm{DE}$} & \multicolumn{2}{|c|}{ - } \\
\hline & & & & \multicolumn{2}{|c|}{ IE } & \multicolumn{2}{|c|}{ - } \\
\hline & & & & \multicolumn{2}{|c|}{ TE } & \multicolumn{2}{|c|}{-} \\
\hline \multicolumn{2}{|l|}{ FC } & \multicolumn{2}{|c|}{0.37} & \multicolumn{2}{|c|}{$\mathrm{DE}$} & \multicolumn{2}{|c|}{0.13} \\
\hline & & & & \multicolumn{2}{|c|}{ IE } & \multicolumn{2}{|c|}{ - } \\
\hline & & & & \multicolumn{2}{|c|}{ TE } & \multicolumn{2}{|c|}{0.13} \\
\hline$\chi^{2}$ & $d f$ & P-value & $\chi^{2} / \mathrm{df}$ & GFI & AGFI & RMSEA & RMR \\
\hline 35.71 & 25 & 0.07615 & 1.60 & 0.98 & 0.96 & 0.033 & 0.027 \\
\hline
\end{tabular}

$\mathrm{DE}=$ Direct Effect, $\mathrm{IE}=$ Indirect Effect, $\mathrm{TE}=$ Total Effect

From the analysis of the Pearson product moment correlation coefficient of all variables used in the analysis, a linear relationship with statistical significance at the level of 0.01 is identified. In addition, the effectiveness of the measurement model given the structure of the latency variables (construct reliability: $\rho C$ ) and the AVE ( $\rho v)$ is evaluated.

The results indicate that every element can explain the variance of each variable with a relatively low AVE $(\rho \mathrm{v}>$ 0.50 ), as evidenced in Table 6.

Taking into consideration the basic terms for analysing the causal influence of the structural equations as detailed above, the data were then analyzed using the LISREL program. According to the results of the analysis of causal influences with latent variables between the strategic intuition capability and the firm performance, it was determined that due to the results of the first data analysis, the model was not consistent with the empirical data. The researcher then adjusted the model until the model was consistent with the empirical data by considering the Chi-square, P-value, GFI, AGFI, RMSEA and RMR as in Table 7.

Table 7 indicates that the Chi-square is 35.71 , and the independent layer of 25 has a probability of 0.07615 . Hence, the result of dividing the Chi-square by the independent layer is 1.60, yielding an index harmony (GFI) equal to 0.98 , an adjusted harmonic index (AGFI) of 0.96 with an RMSEA of 0.033 , and an RMR of 0.027 . Accordingly, the research model is consistent with the empirical data, and thus, it can be presented as a model of the causal relationship between strategic intelligibility and the results of the organization as presented in Figure 2.

\section{Conclusions}

The results of the confirmatory factor analysis of strategic intuition capability reveal that the research model is consistent with the empirical data. Furthermore, the study determined that to find the solution to an identified problem, the sub-components of correct thinking, e.g., indicators, must be employed to identify the most important causes and factors of the problem. Once the problem has been identified, conscious consideration must be given to finding solutions and recognizing what is currently least important while also determining the sub-components of the requisite expertise. One of the most important indicators is possessing both a basic knowledge and an in-depth knowledge of the job to perform one's job on a daily basis. Regarding the sub-components of mental concentration, while important indicators include being completely mindful of what one is doing and being sensitive to the problems and obstacles encountered, an analysis of the confirmed composition of the intelligent expertise is considered to be the most critical sub-component. This is followed by correct thinking and concentration to obtain wisdom in accordance with the principles of Payutto (2003) during the practice of Yonisomanasikara, which serves as a guideline for considering problems that arise.

With respect to the analysis of the path coefficient model of strategic insight and organizational performance, there is no significant influence because the majority of the respondents are entrepreneurs in SMEs, most of which are in the food and beverage business. In essence, these are businesses that operate mainly out of households and exhibit minimal operational profits. Hence, the analysis reflects no connections between strategic insight and the results achieved by Covin and Miles (1999).

\section{Implications}

This paper describes the relationships associated with raising the level of strategic intuition capability of 
entrepreneurs in Thailand to create a competitive advantage (Barney, 1991; Kogut \& Zander, 1992). Developing strategic intuition capability requires that the entrepreneur focus on the development of his/her personal ability to make decisions based on a state of mind that is focused and awake and that consciously engages the thinking processes necessary to lead to an intellectual path. While strategic intuition capability is the foundation for the development of entrepreneurial intelligence as a state of consciousness, the ability to concentrate requires that the mind and body be synchronized and work together to enhance the individual's ability to reach his/her full potential and realize greater efficiency in the work environment.

\section{Limitation}

By studying the relationship between strategic intuition capability and firm performance, it is concluded that there is no statistically significant relationship between the two, a finding that may be due to the limitations of the tools employed by the researchers. For example, ROAs was used to measure the performance of the organization, an instrument that cannot measure other relevant dimensions, such as good relations between customers. While the organization measures the ability of the strategic intuition of entrepreneurs, which is an indicator of personal ability, the evaluation of the performance of the organization is a measure of the efficiency of the organization. Therefore, it is a limitation of this research that it cannot use the results of this study to clearly explain the phenomena that occurred.

\section{References}

Ahangaran, J., Khooshebast, F., \& Vahedi, E. (2016). Metaanalysis of the effects of spirituality in the organization and comprehensive. International Journal of Advanced and Applied Sciences, 3(1), 22-31.

Aujirapongpan, S., \& Jutidharabongse, J. (2017). Strategic intuition: The development of leader in the 21st century. WMS Journal of Management, 6(3), 125-133. https://www.tci-thaijo.org/index. $\mathrm{php} / \mathrm{wms} /$ article/view/99800?articlesBySameAuthorPage=2

Aujirapongpan, S., \& Jutidharabongse, J. (2017). The role of knowledge management in developing strategic intuition. Suratthani Rajabhat Journal, 4(2), 21-44. https://so05.tcithaijo.org/index.php/srj/article/view/212539

Aujirapongpan, S., \& Hareebin, Y. (2020). The effect of strategic intuition, business analytic, networking capabilities and dynamic strategy on innovation performance: The empirical study Thai processed food exporters. Journal of Asian Finance, Economics and Business, 7(1), 259-268. https://doi. org/10.13106/jafeb.2020.vol7.no1.259

Barney, J. (1991). Firm resources and sustained competitive advantage. Journal of Management, 17(1), 99-121.
Brown, S. L., \& Eisenhardt, K. M. (1997). The art of continuous change: Linking complexity theory and time-based evolution in relentlessly shifting organizations. Administrative Science Quarterly, 42(1), 1-34. https://doi.org/10.2307/2393807

Covin, J. O. \& Miles, M. P. (1999). Corporate entrepreneurship and the pursuit of competitive advantage entrepreneurship. Theory \& Practice, 23(3), 47-63. https://doi. org/10.1177/104225879902300304

Crossan, M. M., Lane, H. W. \& White, R. E. (1999). An organisational learning framework: From intuition to institution. The Academy of Management Review, 24(3), 522-537. https:// doi.org/10.5465/amr.1999.2202135

Dane, E. \& Pratt, M. G. (2007). Exploring intuition and its role in managerial decision-making. Academy Management Review, 32(1), 33-54. https://psycnet.apa.org/doi/10.2307/20159279

Duggan, W. (2013). Strategic intuition: The creative spark in human achievement (2nd ed.). New York, NY: Columbia Business School.

Export-Import Bank of Thailand. (2018). SME provincial champions. Retrieved August 21, 2018, https://www.exim. go.th/en/Newsroom/Press-Releases1.aspx

Gannon, C., Lynch, P. \& Harrington, D. (2009). Dynamic knowledge management capability (DKMC): From resources to capital (RIKON Group). In: EIASM 5th workshop on visualising, measuring, and managing intangibles and intellectual capital. http://repository.wit.ie/id/eprint/1468

Grant, R. M. (2003). Strategic planning in a turbulent environment: Evidence from the oil majors. Strategic Management Journal, 24(6), 491-517. https://doi.org/10.1002/smj.314

Greiner, M. E., Bohmann, T. \& Krcmar, H. (2007). A strategy for knowledge management. Journal of Knowledge Management, 11(6), 3-15. https://doi.org/10.1108/13673270710832127

Ha, V. D. (2020). Impact of Organizational Culture on the Accounting Information System and Operational Performance of Small and Medium Sized Enterprises in Ho Chi Minh City. Journal of Asian Finance, Economics and Business, 7(2), 301308. https://doi.org/10.13106/jafeb.2020.vol7.no2.301

Haggie, K., \& Kingston, J. (2003). Choosing your knowledge management strategy. Journal of Knowledge Management Practice, 5(1), 33-42.

Hair, J. F., Black, W. C., Babin, B. J. \& Anderson, R. E. (2014). Multivariate data analysis (7th ed.). Upper Saddle River, NJ: Pearson Prentice Hall.

Hamel, G. (1996). Strategy as revolution. Harvard Business Review, (July-August), 69-82. https://hbr.org/1996/07/strategyas-revolution

Hodgkinson, G. P., Smith, E. W., Burke, L. A., Claxton, G. \& Sparrow, P. R. (2009). Intuition in organizations: Implications for strategic management. Long Range Planning, 42, 277-297. https://doi.org/10.1016/j.lrp.2009.05.003

Kogut, B., \& Zander, U. (1992). Knowledge of the firm, combinative capabilities, and the replication of technology. Organization Science, 3(3), 383-397. https://doi.org/10.1287/orsc.3.3.383 
Kouzes, J. M., \& Posner, B. Z. (2012). The leadership challenge: How to make extraordinary things happen in organizations (5th ed.). San Francisco, CA: Jossey-Bass.

Meers, K. A., \& Robertson, C. (2007). Strategic planning practices in profitable small firms in the United States. The Business Review Cambridge, 7(1), 302-307.

Miller, C. C. \& Cardinal, L. B. (1994). Strategic planning and firm performance: A synthesis of more than two decades of research. Academy of Management Journal, 37(6), 1649-1665. https:// doi.org/10.2307/256804

Miller, C. C., \& Ireland, R. D. (2005). Intuition in Strategic Decision-making, Friend or Foe in the Fast-Paced 21 st Century. Academy of Management Executive, 19(1), 19-30. https://doi. org/10.5465/ame.2005.15841948

Nocker, M. \& Sena, V. (2019). Big Data and Human Resources Management: The Rise of Talent Analytics. Social Sciences, 8(10), 273-291. https://doi.org/10.3390/socsci8100273

Payutto, P. A. (2003). The way of thinking according to Buddhist principles. (9th ed.). Bangkok: Thammasat.

Payutto, P. A. (2012). Dictionary of Buddhism (32nd ed.). Bangkok: Mahachulalongkornrajavidyalaya University.
Rompho, N. (2018). Operational performance measures for startups. Measuring Business Excellence, 22(1), 31-41. https:// doi.org/10.1108/MBE-06-2017-0028

Srichan, T., Tachaphahapong, S., \& Methakunavudhi, P. (2016). A factor analysis of leadership in the twenty first century of student organization board. Journal of Research Methodology, 29(2), 1-17.

Teece, D. J. (2018). Business models and dynamic capabilities. Long Range Planning. 51(1), 40-49. https://doi.org/10.1016/j. lrp.2017.06.007

Venkatraman, N., \& Ramanujam, V. (1986). Measurement of business performance in strategy research: A comparison of approaches. Academy of Management Review, 11(4), 801-814. https://doi.org/10.2307/258398

Yi, H. T., Han, C. N., \& Cha, Y. B. (2018). The Effect of Entrepreneurship of SMEs on Corporate Capabilities, Dynamic Capability and Technical Performances in South Korea. Journal of Asian Finance, Economics and Business, 5(4), 135147. http://doi.org/10.13106/jafeb.2018.vol5.no4.135

Zack, M. H. (1999). Developing a knowledge strategy. California Management Review, 41(3), 125-145. 